\title{
ERRATUM
}

H. Kyröläinen · P. V. Komi

\section{Differences in mechanical efficiency between power- and endurance-trained athletes while jumping}

Eur J Appl Physiol (1994) 70:36-44

Due to an unfortunate error, Fig. 6 (together with its legend) was published twice - as Fig. 6 and as Fig. 7.

The correct Fig. 7 appears below, together with its legend.

Fig. 7 Averaged signals of reaction force, ankle angle and rectified EMGs from the soleus $(S O L)$ and vastus lateralis $(V L)$ during the drop jumps. The left hand curves are from a power athlete and the right hand ones are the respective curves from an endurance athlete. The lowest line for every group of signals is the condition of $\mathrm{O}-40$, the middle line is the optimum $(\mathrm{O})$ and the top one is the condition of $\mathrm{O}+40$. For definition of these terms, see the Methods section

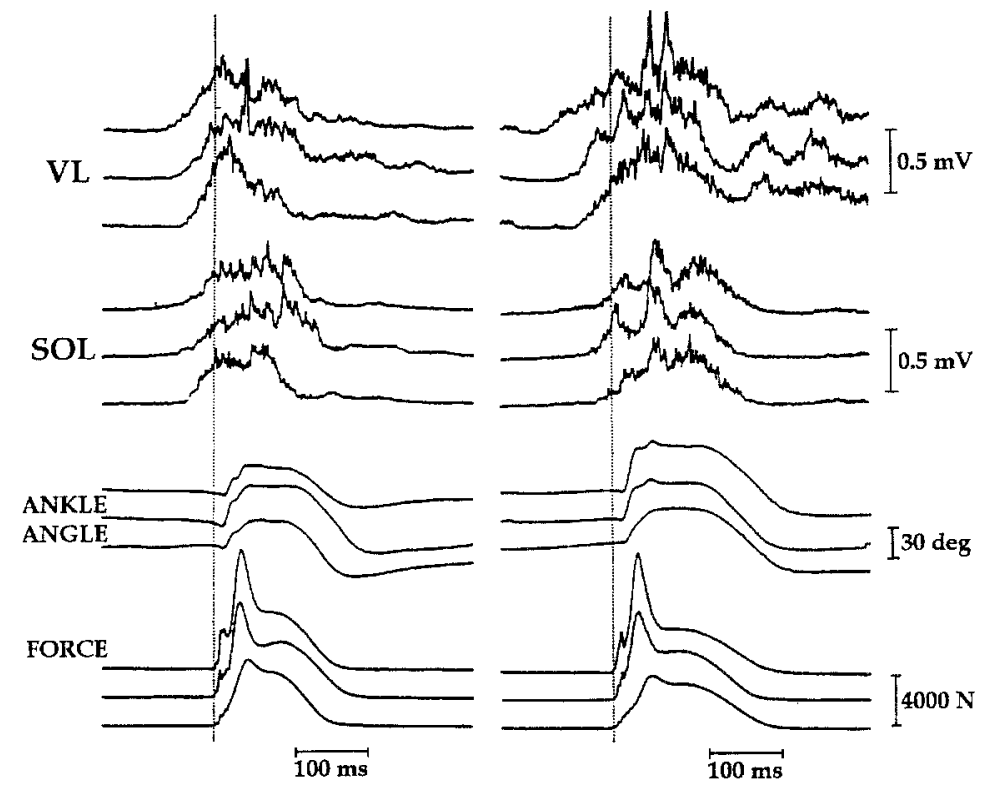

